\title{
Polyneuritis cranialis associated with industrial trichloroethylene poisoning
}

\author{
PETER H. BUXTON AND MICHAEL HAYWARD \\ From the Neuropathology Laboratory and Regional Neurological Centre, Walton Hospital, Liverpool
}

Trichloroethylene came into wide use as a solvent and degreasing agent during the First World War, and in 1915 the first cases of cranial nerve damage in workers exposed to this substance were reported. Further reports followed and it was suggested that the toxic agent was a contaminant (Defalque, 1961; Browning, 1965). Jackson (1934) published an account of the anaesthetic properties of trichloroethylene, but the Council on Pharmacy and Chemistry of the American Medical Association (1936) criticized his use of this substance because of the earlier reported cranial nerve palsies and inhibited its use as an anaesthetic agent in the United States. Five years later Hewer and Hadfield (1941) introduced it into British anaesthetic practice and a number of cases of cranial nerve damage occurred. It soon became evident that in these cases the use of soda lime in closed circuit was the causative factor, as it led to decomposition of the drug (Firth and Stuckey, 1945). Avoidance of such conditions effectively prevented any further mishaps. The pathology of the cranial nerve lesions has not been previously described; the only necropsies available were two in the series of Humphrey and McClelland (1944).

\section{ACCIDENTAL EXPOSURE TO FUMES}

In this communication we describe an industrial accident with trichloroethylene involving four men, the most severely affected of whom died after 51 days; the necropsy findings are described in detail.

The accident occurred while the boiler feed tanks of a frigate in dock for a refit were being emptied. Several independent tanks form a closed system with the boiler and are not directly interconnected. After the bulk of water is drained from each tank a scaler enters with a bucket to take up the last few inches, passing his moppings to a second man outside.

At the start of this operation strong fumes were noted and an analytical chemist investigating a boiler tube deposit provisionally identified the emanant as trichloroethylene. In his subsequent analysis of the deposit he confirmed the presence of trichloroethylene which had dissolved aluminium paint from the interior of the tanks. Specialist operators cleared the first tank wearing fresh air respirators, but later the same day, when successive tanks were emptied, the same precautions were not observed. The four scalers who performed this task all noted unpleasant fumes but continued with their habitual job in a stoical way. The severity of symptoms that each developed was directly related to the length of time he spent within the confines of the tanks exposed to the fumes.

\section{CASE REPORTS}

CASE 1 A man, aged 44 years, collected the buckets from his mates and estimates that he spent about ten minutes within the tanks. He felt quite well that evening but the next morning awoke with severe generalized headache and nausea which persisted for $\mathbf{4 8}$ hours. On the third day he felt well enough to return to work and had no further complaints. He did not consult a doctor.

CASE 2 A man, aged 39 years, spent about 30 minutes within the tanks. He found the fumes so disagreeable that thereafter he confined himself to assisting from without. On leaving the job he felt 'sick and half doped' and he vomited on the way home. The following day he states that he broke out in blisters around the mouth and that part of his face became numb. He was treated by his general practitioner, and was not seen at hospital. After 15 days he returned to work, his symptoms having subsided.

CASE 3 A man, aged 43 years, worked inside the tanks for two and a half hours in all, coming out at intervals for a breath of fresh air. On leaving the job he felt dizzy and intoxicated and fell over while trying to kick-start his motor bicycle. Twenty-four hours after exposure he noticed numbness and tingling commencing in the upper lip and gradually spreading over the face and forehead, the upper gum and palate. He was first seen at the Neurological Unit at Walton Hospital on day 6, his symptoms being unchanged. At this stage he was found to have blunting to pinprick over the first two divisions of the trigeminal distribution and slight weakness of the right facial muscles. Vitamin $B_{12}$ injections were pre- 
scribed and he returned for review on day 8 when he was admitted to the ward.

On admission his symptoms had progressed considerably and he was found to have photophobia with pain on ocular movement, bilateral ptosis, and right external rectus weakness with diplopia. The pupils were central, regular, equal, reacting to light and accommodation, and there was no nystagmus. The fundi appeared normal and the peripheral fields were full but on the right the blind spot was enlarged and on the left there was a paracentral scotoma with constriction of the central fields. He had trigeminal motor weakness and bilateral facial weakness. Hearing was normal but the sensation of taste was absent over the anterior tongue. There was no clouding of consciousness nor impairment of his mental faculties. In the limbs the motor and sensory systems were quite normal, the tendon reflexes being retained and the plantar responses flexor.

Following admission, nausea, present from the time of exposure, started to improve, but his general condition continued to deteriorate and on day 9 the facial diplegia was more marked and he was unable to protrude his tongue fully. His gag reflexes remained present although he was unable to swallow solids for several weeks. The cranial nerve symptoms did not improve at all for at least a month, and thereafter only very slightly. When he left hospital 10 weeks after exposure he was still gravely disabled. Symptomatic therapy included a course of corticosteroids, initially Prednisone $10 \mathrm{mg}$. t.d.s., which did not appear to influence the course of his illness.

On assessment two and a half years after the incident he has signs of considerable residual damage to cranial nerves. His most troublesome complaint is of peculiar distressing discomfort present continuously around the mouth and in the cheeks with numbness of the upper lip, gum, and palate. Impaired reaction to pinprick remains. He has not regained his sense of taste and his vision is altered, objects appearing dimmer through the left eye. Bright lights cause ocular pain and he prefers to wear tinted spectacles. He has slight bilateral facial weakness still and is unable to open his mouth fully or protrude his tongue fully.

The unremitting facial discomfort, the psychological trauma of the unpleasant illness, the death of his colleague, and the protracted litigation have probably all played a part in the production of neurotic traits in this unfortunate man. He has episodes of severe headache, nausea, and vomiting which have prevented him from seeking employment. It is doubtful if he will return to work again. $\mathrm{He}$ is unable to cohabit with his wife because he becomes more acutely aware of his facial discomfort. Before the incident he was a stable man in robust health.

Investigations On the sixteenth day his urinary excretion of trichloracetic acid was $3.5 \mathrm{mg}$. per $100 \mathrm{ml}$. over 24 hours, which is consistent with his having absorbed a quantity of trichlorethylene 16 days earlier. Serial electroencephalographs from the twelfth day to the second year show no change in character. The initial record showed a normally responsive alpha rhythm at 9-10 c/s. Theta components at 4-5 c/s were present, symmetrical, with similar characteristics to the alpha rhythm and were within normal limits.
CASE 4 A man, aged 39 years, probably spent about four hours inside the tanks. At no time was he in the same tanks as case 3 , but there were strong fumes where he worked. On signing off he reported to the first aid post complaining of severe headache, dizziness, and unsteadiness. The attendant commented that he appeared as if drunk. He was admitted directly to Bootle General Hospital and over the following days developed multiple cranial nerve lesions. By day 2 he had diplopia, by day 3 circumoral numbness, by day 6 facial diplegia and loss of gag and swallowing reflexes. By day 8 he could hardly speak and on day 12 tracheostomy was performed to relieve laryngeal obstruction. At this stage he was transferred for nursing care to the Respiratory Insufficiency Unit at Fazakerley Hospital.

On transfer he was noted to have bilateral ptosis with limitation of eye movement in all directions. The pupils were central, equal and regular, reacting to light and accommodation. The fundi appeared normal but detailed investigation of the visual acuity and fields was not possible. His face was analgesic and the corneal reflexes were absent. Trigeminal motor power was reduced and the pharynx totally anaesthetic. He had moderate facial diplegia. His hearing was not apparently affected. He was unable to protrude his tongue, the vocal cords were almost completely paralysed, and the cough and gag reflexes were absent. In the trunk and limbs there was slight generalized weakness. The tendon reflexes were difficult to elicit. The plantar responses were flexor. Coordination was normal and the sensory system unaffected.

Nausea persisted from the time of his admission and he vomited many times each day despite large doses of chlorpromazine and other anti-emetic drugs. Despite parenteral feeding it was impossible to maintain his nutrition adequately. He would often turn off the intra-? gastric drip because a small quantity of fluid in the stomach made him vomit. Additionally he suffered from recurrent respiratory infections, having no cough reflex. His respiratory rhythm was not disturbed and he did not require aided respiration. His mental state remained clear until late in the illness when he succumbed to respiratory infection. The heart rate was consistently raised, being around 96 per minute at rest and rising to 160 per minute with infections. A short course of corticosteroids, initially hydrocortisone $100 \mathrm{mg}$. twice daily, did not appear to affect the course of his illness.

Investigations on admission Haemoglobin $15.8 \mathrm{g.} \%$, white cells 13,600 (polymorphs $80 \%$ ); S.G.O.T. 26 units/ ml., thymol turbidity 1 unit; alkaline phosphatase 10 units. Blood sugar estimations were within normal limits. There was some transitory renal impairment with moderate albuminuria, the urine contained $0.25 \%$ glucose, numerous oxalate crystals but no pus or casts; the blood urea was $65 \mathrm{mg} . / 100 \mathrm{ml}$.

\section{POST-MORTEM FINDINGS IN CASE 4}

The body was that of a very emaciated middleaged man. No abnormality was seen or felt in the brain. A thinly purulent right pleural effusion was present and the lower lobe of the right lung showed confluent bronchopneu- 
monia. Both upper lobes showed less severe pneumonic changes.

The liver (weight $1,800 \mathrm{~g}$.) showed slight fatty pallor. The heart (weight $295 \mathrm{~g}$.), the kidneys (weight $170 \mathrm{~g}$. each), and other organs appeared normal.

Microscopy Sections of the lungs showed acute and subacute bronchopneumonia. The liver (Fig. 1) showed extensive fatty change rather more in the peripheral part of the lobules than centrally; slight round cell infiltration of the portal tracts was present. Kidney sections showed no abnormality other than irregular shrinkage of some distal tubule cells attributable to post-mortem change. Heart muscle showed mild toxic change.

No significant abnormality was seen in suprarenals, thyroid, spleen, or pancreas.

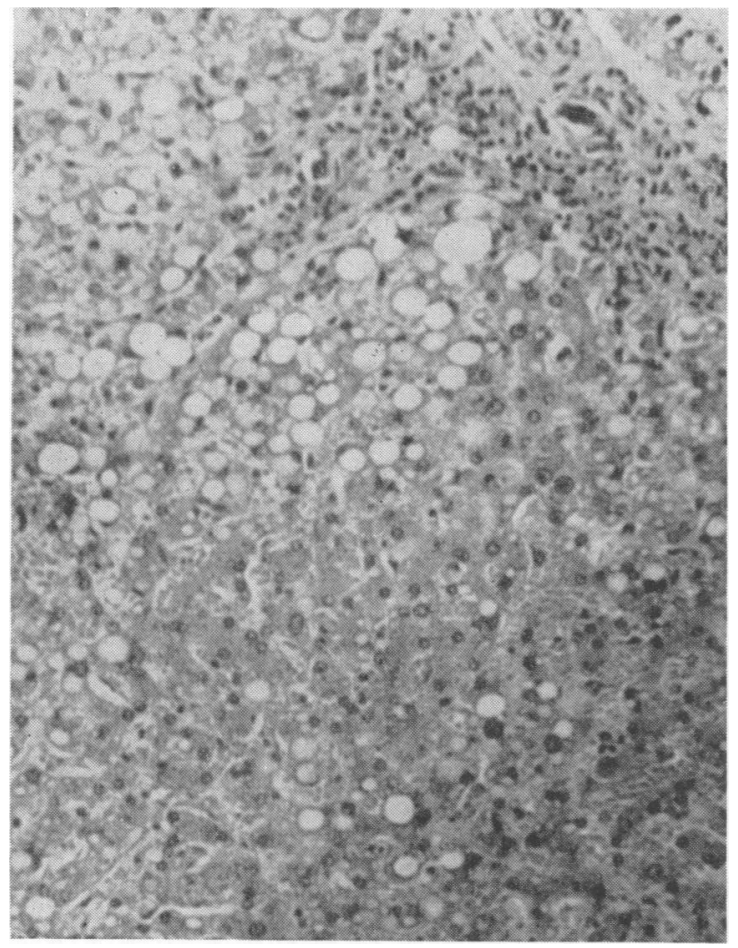

FIG. 1. Liver showing round cell infiltration of portal tract and fatty change. Haematoxylin and eosin $\times 180$.

Central nervous system The cerebrum had been cut fresh horizontally when no abnormality was seen. After fixation for one month in $10 \%$ buffered formalin, coronal sections of frontal, temporal, parietal, and occipital regions were taken. The brainstem, cerebellum, and spinal cord were sectioned transversely. Most of the material was paraffin embedded but representative blocks were taken for frozen sections.

The stains used on paraffin-embedded material were haematoxylin and eosin, Nissl's cresyl violet, Heidenhain stain for myelin, Luxol blue and Holme's silver nitrate for axons with myelin sheaths, phosphotungstic acid haematoxylin, and Holzer's crystal violet for glial fibres;

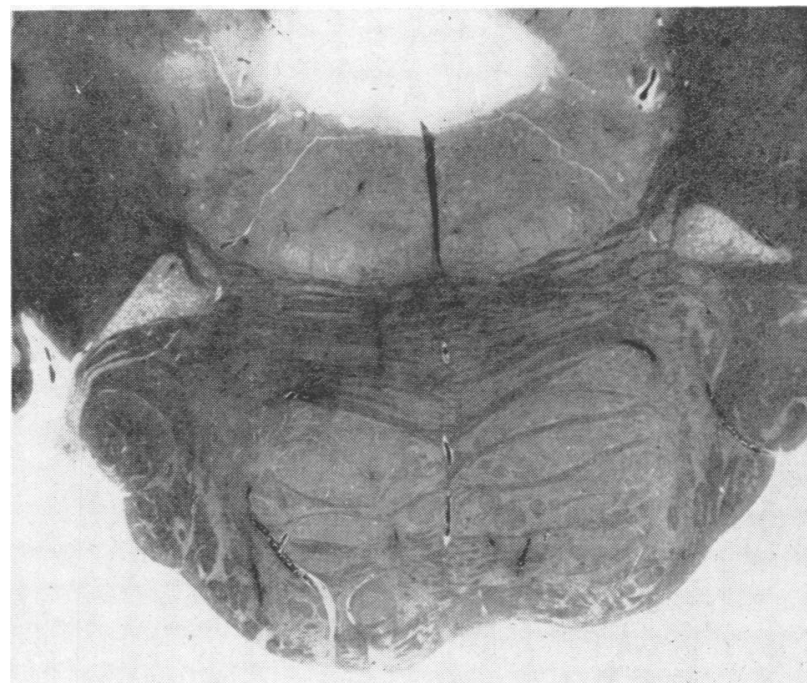

FIG. 2. Pons transverse section showing symmetrical demy elination of fifth nerves intra- and extracranially. Heidenhain's myelin $\times 2 \frac{2}{3}$.

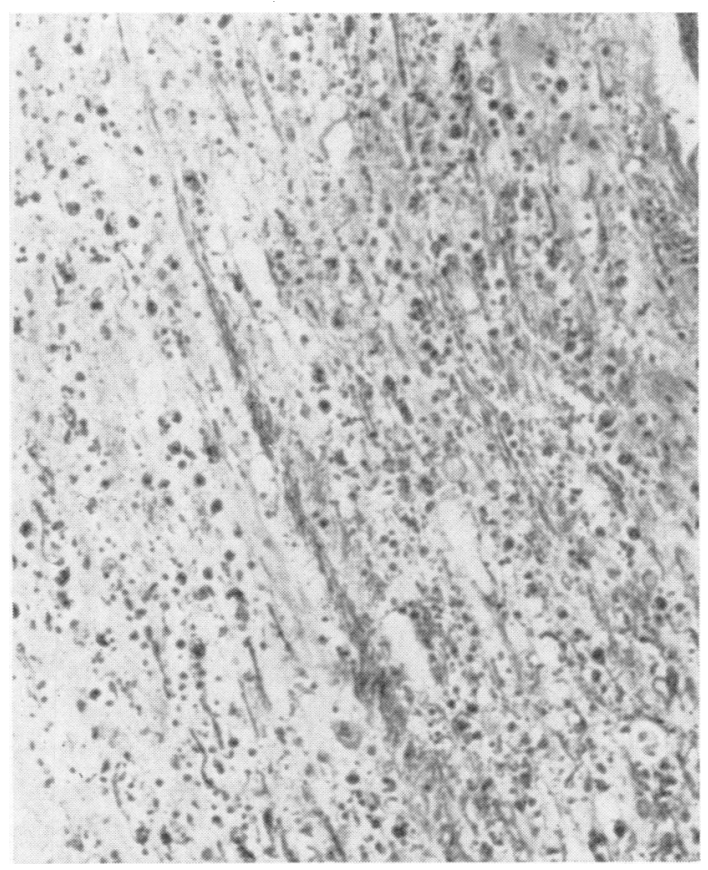

FIG. 3. Fifth nerve emerging form brainstem showing myelin loss and axon damage. Luxol blue and Holme's silver nitrate $\times 160$. 


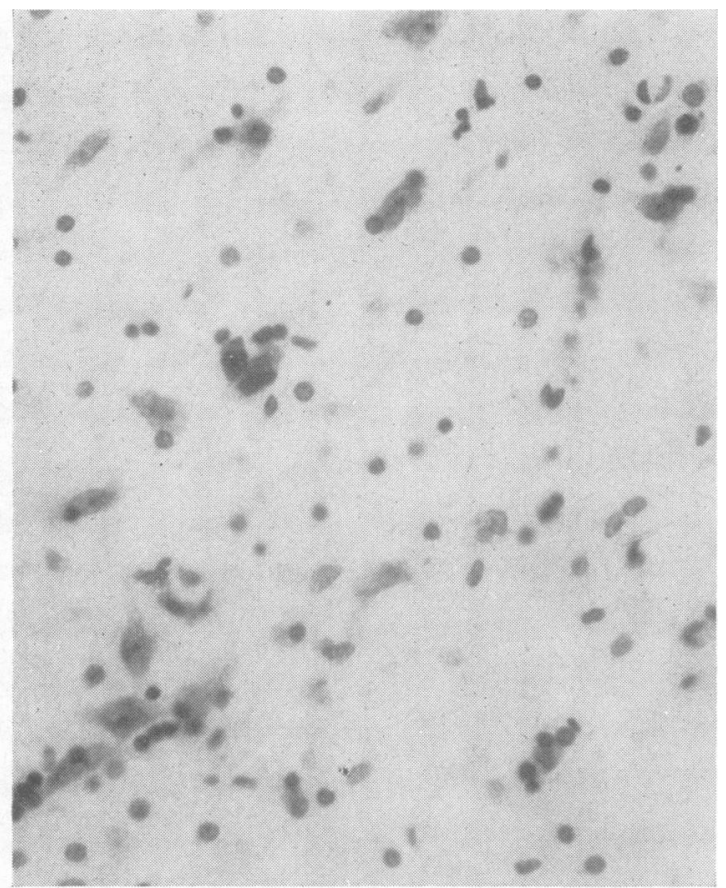

FIG. 4. Principal sensory nucleus of fifth nerve showing satellitosis, degenerative changes, and sparsity of neurones. Nissl $\times 300$.

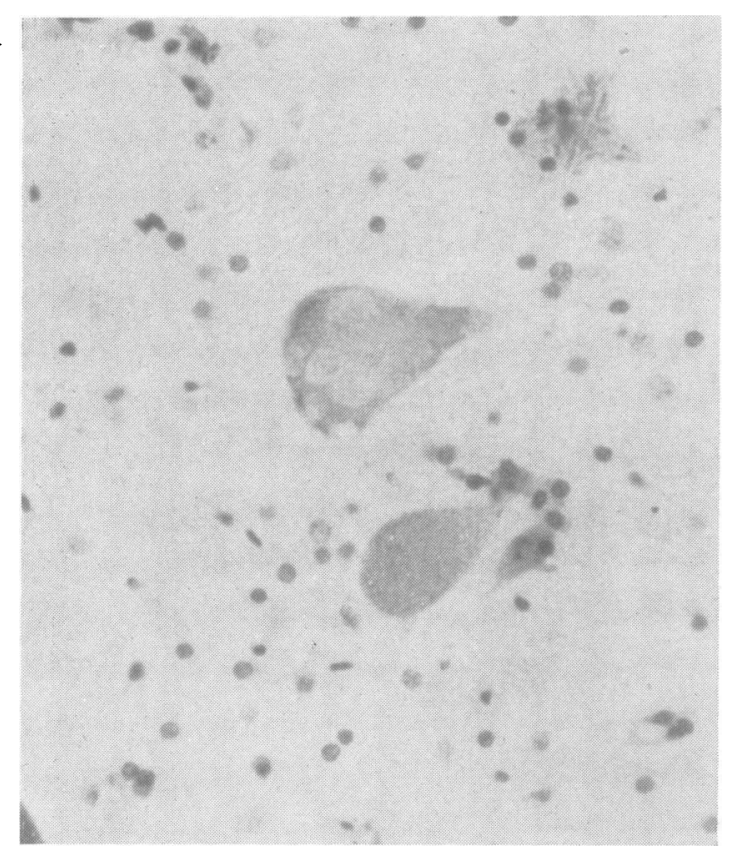

FIG. 5. Motor nerve cells of fifth nerve nucleus showing vacuoles in the cytoplasm of a nerve cell. Nissl $\times 300$. on frozen sections, oil red $O$, periodic-acid Schiff, buffered toluidine blue, Bielchowsky's silver hydroxide method for axis cylinders, and Cajal's gold sublimate method for astrocytes were used.

The most striking changes were seen in the brainstem in the fifth nerve nuclei, spinal tracts, and nerve roots (Fig. 2). The changes were at all levels bilateral and symmetrical. The fifth nerves both within and outside the brainstem showed extensive myelin and axon degeneration. In luxol blue and silver preparations scarcely any myelinated axons remained, myelin was aggregated into irregular globules, the axons were much reduced in number, and irregular in size, some with varicosities (Fig. 3). The principal sensory and spinal tract nuclei of the fifth nerve showed severe nerve cell loss, and homogenizing change in a few remaining neurones (Fig. 4). There was very little glial reaction, no inflammatory change, and the blood vessels appeared normal. In much of this region, the extensive damage resulted in a spongiose appearance. The motor nuclei of the fifth nerve also showed some cell loss and homogenizing change but normal nerve cells were still present. A few neurones showed clear vacuoles in their cytoplasm; these vacuoles failed to stain with acidic or basic dyes or by the periodic-acid Schiff method (Fig. 5).

In the lower pons many of the nerve cells of the sixth nerve nuclei showed homogenizing change and hyperchromatic shrinkage, but morphologically normal nerve cells remained (Fig. 6). Similar though less severe changes were seen in the seventh nerve nuclei. Degenerative changes were also seen in the lateral and superior vestibular nuclei and in the nuclei giganto-cellularis and the superior olives. At the lower border of the pons the sixth nerve was seen in cross section, and showed marked swelling of myelin sheaths (Fig. 7).

In the medulla, degeneration of the fifth nerve spinal tract and nucleus was the most striking feature, but degeneration of the tract and nucleus solitarius and cuneate nuclei was also seen with less marked changes in the dorsal motor nuclei of the vagus and the hypoglossal nuclei. Some nerve cell loss and satellitosis was apparent in the reticular formation.

In the midbrain no gross changes were seen. Many neurones of the third nerve nuclei appeared normal though there were some shrunken and distorted forms.

The red nucleus, substantia nigra, and mammillary bodies showed slight nerve cell loss and glial increase; the changes were most marked in the lateral mammillary nuclei and posterior hypothalamic nuclei.

In the thalamus and in the putamen satellitosis was prominent, but without significant nerve cell loss. The globus pallidus showed more marked neuronal loss, and homogenizing change in remaining neurones particularly in the pars lateralis.

Cerebral cortex Sections were taken from frontal, temporal, parietal, occipital, and Ammon's horn regions. The laminar pattern was well preserved, but there was hyperchromatic shrinkage of occasional neurones mainly in the third and fifth laminae and moderate general glial increase. This neuronal change was rather more prominent in Sommer's sector and end plate region of Ammon's horn, but was not gross. 


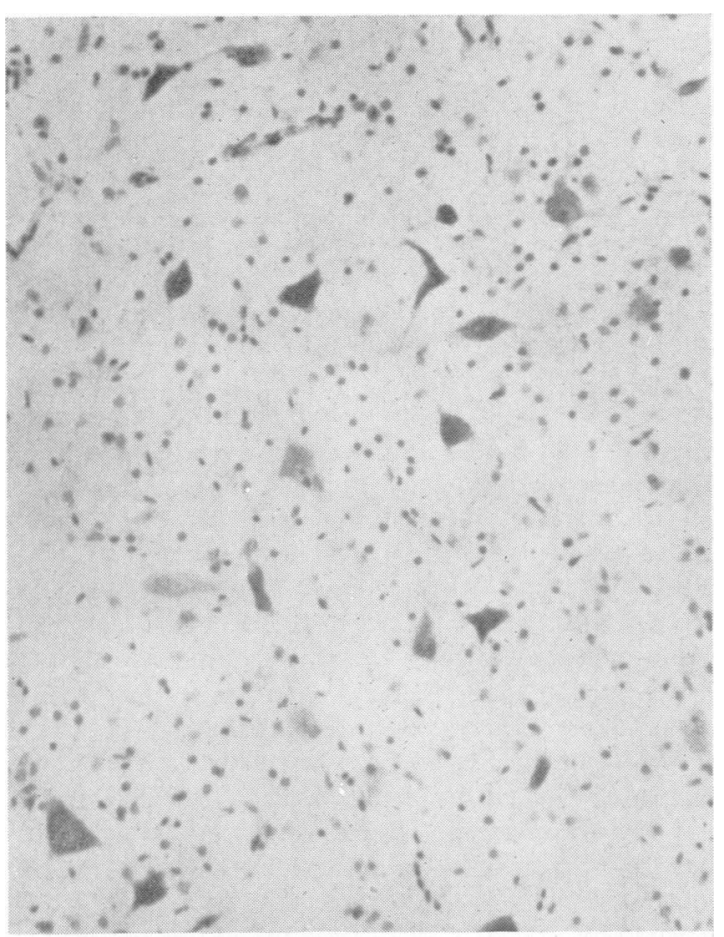

FIG. 6. Sixth nerve nucleus showing many degenerate but some normal neurones. Nissl $\times 180$.

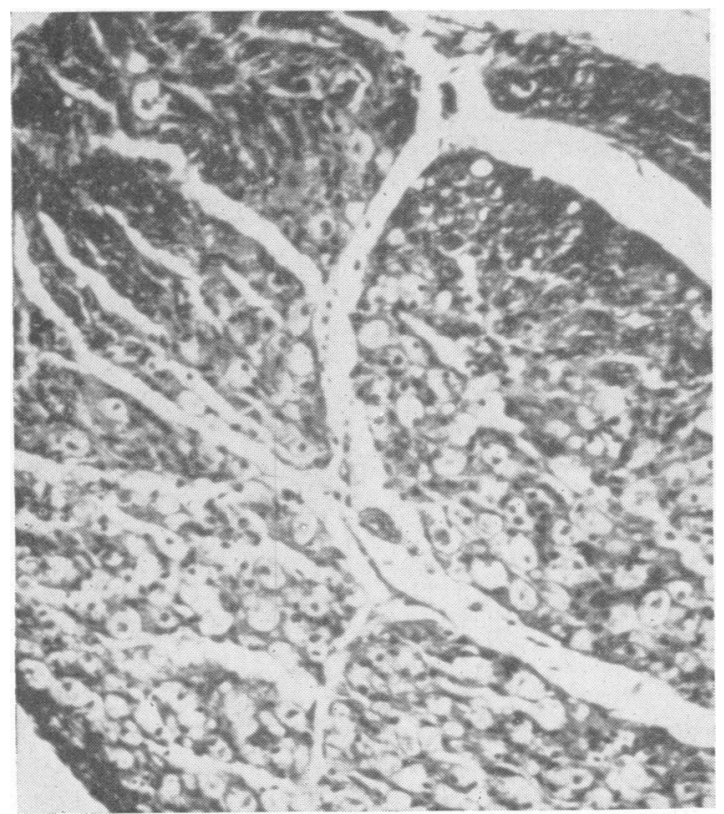

FIG. 7. Sixth nerve cross section at lower border of pons showing swelling of myelin sheaths. Heidenhain's myelin $\times 160$.
The cerebellum showed some Purkinje cell loss and slight increase in Bergmann astrocytes. The dentate nucleus showed mild neuronal loss with glial increase.

Spinal cord Sections from the upper cervical, cervical enlargement, upper and mid thoracic, and lumbar enlargement were examined. In the upper cervical region the substantia gelatinosa showed mild spongiose change and neuronal loss which extended slightly into the fasciculus cuneatus, but below this no significant abnormalities were seen in the tracts. There was slight reduction in the number of anterior horn cells and increase of degenerate forms showing chromatolysis and shrinkage, particularly in the region of the cervical enlargement.

Anterior and posterior nerve roots were examined throughout the cord but no abnormalities were found. No posterior root ganglia were available.

Glial reaction Holzer stain showed no mature glial fibre formation even in the region of the grossly degenerate fifth nerve nuclei and tracts, although frozen sections stained by Cajal's gold sublimate method for astrocytes did show slight glial increase in some of these areas.

Myelin breakdown products In frozen section material, oil red 'o', periodic acid Schiff, and buffered toluidine blue stains showed no significant breakdown products of myelin.

SUMMARY OF POST-MORTEM FINDINGS The most severe damage occurred in the brainstem, the fifth nerves, tracts and nuclei, particularly the sensory divisions. Also affected were the nucleus and tractus solitarius and to a less extent some of the other dorsal brainstem nuclei and the reticular formation.

The changes in the cerebral cortex and cerebellar cortex were less severe and were compatible with secondary hypoxaemia.

CLINICO-PATHOLOGICAL CORRELATION These changes found at necropsy in the brainstem in case 4 correlate very well with the clinical features of involvement of the sensory division of the fifth nerve, diplopia, facial weakness, and difficulty in swallowing. The persistent tachycardia and reflex vomiting might well have been due to the involvement of vagal nuclei. Clinically there was no indication of peripheral nerve involvement arart from depressed tendon reflexes which could also be accounted for by involvement of the brainstem reticular formation. Peripheral nerves and dorsal root ganglia were not available for examination, but only minor abnormalities were seen in the grey and white matter of the spinal cord, other than the degenerative changes in the descending root of the fifth nerve in the upper cervical region. Many anterior and posterior nerve roots were examined and these showed no degenerative change.

\section{DISCUSSION}

Industrial surveys have revealed a number of examples of isolated and otherwise unexplained facial numbness in workers exposed to trichloroethylene. Stüber (1931) found 10 cases among 284 at risk: Grandjean, Münchinger, Turrian, Haas, 
Knoepfal, and Rosenmund (1955) found none in a survey covering 80 workers: Andersson (1957) found one transient case from 104 at risk. In addition there have been two industrial incidents with immediate relationship to a single exposure to fumes. Plessner (1915) described four men exposed while cleaning shell cases to a mixed solvent containing $75 \%$ trichloroethylene. They vomited profusely and shortly after developed trigeminal dysaesthesia which had not resolved after eight months. Kalinowski (1927) described two men with similar features after cleaning out an acetylene-producing plant but here trichloroethylene was not directly involved. No further multiple incidents have since been reported from industry. The decrease in incidence of this complication is certainly not due to lessened exposure as the commoner complication of narcosis still occurs, but must be accounted for by increased purity or differing methods of using the solvent in modern industrial practice (Browning, 1965).

These early cases of trigeminal analgesia led to the introduction of trichloroethylene inhalations as a supposed specific therapy for trigeminal neuralgia, a mode of therapy which remained in vogue for some years (Oljenick, 1928; Glaser, 1931). At this time the non-specific analgesic effects of the pure substance were not generally recognized.

The largest and best documented group of patients with toxic cranial nerve palsies are those which followed anaesthesia in which soda lime had been used in closed circuit. Full details have been reported of 20 such cases (McCauley, 1943; Humphrey and McClelland, 1944; Carden, 1944; Enderby, 1944). A particular brand of soda lime that heated excessively during use was frequently involved. In several cases the trichloroethylene or toxic product had been carried over in the apparatus from a previous anaesthetic. Details of the technique of administration, which might be relevant to the site of absorption of the toxin, are not often given but there is specific mention of the use of a nasotracheal tube or an endotracheal tube in certain cases. The clinical course of these patients is comparable to that of our cases; $50 \%$ vomited excessively after operations; there was typically a delay of 24 hours before the onset of facial numbness, and trigeminal sensory disturbance was the earliest and most prominent symptom. Twelve of the patients developed facial herpes, attributed by Humphrey and McClelland (1944) to provocation of latent herpes simplex virus. Of our cases only case 2 developed herpes. Facial herpes is common following trigeminal sensory root section. Carton and Kilbourne (1952) isolated herpes simplex virus from the facial vesicles but failed to do so from excised trigeminal ganglia. Antibody studies in several of their patients indicated that all so examined had had previous infection and they concluded that section of trigeminal sensory roots, perhaps by altering tissue metabolism in some way, reactivated previously existent herpes simplex virus.

Hewer (1943) alludes to mild transitory cases of trigeminal sensory disturbance following anaesthesia but the more severe cases described in the literature generally improved very little. Dillon (1956) described the case of a patient who had been instructed to inhale trichloroethylene for the relief of pain from a metastatic deposit. She left the bottle, unused, exposed to sunlight on her dresser for a month; then three days after inhaling from it she developed numbness over the third division of the trigeminal nerves which did not fully regress.

The only previously reported necropsies in this condition were in the series of Humphrey and McClelland. Case 8 died after 48 hours: oedema of the brainstem was found but no significant changes in the grey matter. Case 11, a uraemic man of 74 years, died 16 days after a cystotomy. Clinically many cranial nerves were affected but not severely. Necropsy showed brainstem oedema and glial stars, non-specific changes, which might well have been due to terminal respiratory embarrassment. These authors concluded that they had found no clear histological evidence as to the cause of the condition.

There is no doubt clinically that the illness in our cases and the specific changes found at necropsy in case 4 were due to a toxin related to the inhalation or local absorption of industrial trichloroethylene or some breakdown product. The most notable features are the delay in the development of the full clinical picture and the selectivity of the toxin on the brainstem nuclei, particularly the fifth. There is also no doubt from common anaesthetic practice that pure trichloroethylene does not cause cranial nerve palsies. Certain physical conditions such as exposure to heat, light, alkalis, and divided metal catalysts, cause the otherwise stable compound to decompose (Browning, 1965). The evidence as to which of the decomposition products is responsible for the neurotoxic effects is inconclusive: dichloroacetylene (D.C.A.), a highly explosive gas, was said by Hunter (1944) to be the only substance produced in any quantity in the circumstances of anaesthesia with soda lime. Firth and Stuckey (1945) went on to point out that when moisture was present in the circuit no D.C.A. was detected, although the trichloroethylene continued to be broken down. They assumed that the D.C.A. had been hydrolysed but did not take the work further. Dichloroacetylene has never been shown to produce specific lesions in the nervous system of experimental animals and there is very little published on its toxicology. The non-specific effects seen by Humphrey and Mc- 
Clelland and Hunter in the brains of their animals do not help in deciding whether this substance might be responsible for the cranial nerve palsies. Siegel (1967) exposed rats to D.C.A. and produced severe damage in other organs but no specific effects in the central nervous system.

It has been suggested that the selective effect of the toxin on the fifth and bulbar nerves might be due to absorption through the skin and mucous membranes of the nasopharynx where there would be a high concentration during anaesthesia; the absorbed toxin might then affect peripheral nerves locally resulting in dying back of the neurones. This hypothesis seems unlikely in the present cases where fumes were in contact with wide areas of the body, and in those anaesthetic cases where administration was by intubation the vapour would not have reached a high concentration in the nasopharynx. If the effect of the toxin were determined by local absorption it is surprising that anosmia was not a more prominent symptom.

The role of hypoxaemia was considered in case 4 and could well explain the cerebral and cerebellar cortical changes, but hypoxaemia is not relevant to cases 2 or 3 and the brainstem changes in case 4 were disproportionately severe and selective in the absence of any anomaly of vascular supply.

The general lack of improvement in the more severe cases suggests that the toxin acts predominantly on the cranial nerve nuclei rather than on the axons or Schwann cells, and the very severe cell loss in the sensory nuclei of the fifth nerve in case 4 supports this view. The survival of many nerve cells in the motor nuclei of the cranial nerves, despite severe clinical symptoms, is perhaps in favour of a peripheral effect. On the evidence at present available we prefer the hypothesis of predominant central action, but proof must await identification of the responsible toxic breakdown product

The delay in onset of the symptoms suggests the slow development or release of a toxic metabolite within the body or perhaps the progressive depletion of some substance essential for neuronal metabolism. The hepatic damage in case 4 may be relevant to this.

There is a precedent for suggesting specific susceptibility of the fifth nerve to systemic toxins. Stilbamidine, a drug introduced for the treatment of antimonal resistant kala-azar (Adams and Yorke, 1939), produced an unpleasant trigeminal sensory disturbance three to four months after a course of intravenous injections (Sen Gupta, 1943; Collard and Hargreaves, 1947). This complication occurred in $80 \%$ of the British series. Such symptoms are characteristic of the trichloroethylene cases and like them improve very little. Stilbamidine has been given for the relief of trigeminal neuralgia (Smith and Miller, 1955). The drug is no longer used for this purpose as unpleasant paraesthesiae, burning and shooting pains, not only in the sensory divisions of the fifth nerve but also in the neck, may accompany its use (Goldstein, Gibilisco, and Rushton, 1963). The long delay in the development of symptoms in the Stilbamidine cases and the route of administration of this drug are strong presumptive evidence of susceptibility of the fifth nerve sensory nuclei to certain toxins and suggest that these cells may depend for their continuing function on specific enzymatic processes.

\section{CONCLUSIONS}

Under certain physical circumstances trichloroethylene may be decomposed to a toxic substance causing cranial nerve palsies which may be irreversible. The toxin is still unidentified but we believe that it is absorbed through the lungs and exerts a central effect on the cranial nerve nuclei, particularly the sensory nuclei of the fifth nerve. This is comparable clinically to the even longer delayed effects of Stilbamidine injection although we have found no record of a histological demonstration of the latter. No satisfactory experimental work on the toxicology of the relevant trichloroethylene breakdown products has been published, particularly concerning their effects on the central nervous system.

\section{SUMMARY}

An industrial incident is described in which four men were exposed to trichloroethylene breakdown products. Two developed severe multiple cranial nerve palsies, one of whom died after 51 days. At necropsy striking changes were found in the brainstem nuclei, tracts, and emergent cranial nerves. The nature and possible modes of action of the toxin are discussed and the previous literature is reviewed. The identity of the toxin is still undecided.

For much of the clinical information and permission to report these cases we are most grateful to Dr. Evans of Bootle Hospital and Dr. Christie of Fazakerley Hospital under whose care case 4 was investigated, and Dr. Slatter of Walton Hospital who cared for case 3. Dr. Charles St. Hill performed the necropsy in case 4 , and kindly provided the material for histological investigation.

\section{REFERENCES}

Adams, A. R. D., and Yorke, W. (1939). A case of Indian kala-azar treated with $4: 4^{\prime}$-diamidino-stilbene. Ann. trop. Med. Parasit., 33, 323-326.

Andersson, A. (1957). Gesundheitliche gefahren in der Industrie bei Exposition für Trichloräthylen. Acta med. scand., 157, suppl. 323, p. 161 . 
Browning, E. (1965). Trichloroethylene. In Toxicity and Metabolism of Industrial Solvents, pp. 189-212. Elsevier, Amsterdam.

Carden, S. (1944). Hazards in the use of the closed-circuit technique for trilene anaesthesia. Brit. med.J., 1, 319-320.

Carton, C. A., and Kilbourne, E. D. (1952). Activation of latent herpes simplex by trigeminal sensory-root section. New Engl. J. Med., 246, 172-176.

Collard, P. J., and Hargreaves, W. H. (1947). Neuropathy after stilbamidine treatment of kala-azar. Lancet, 2, 686-688.

Council on Pharmacy and Chemistry of the American Medical Association (1936). The use of trichloroethylene for general anesthesia. J. Amer. med. Ass., 107, 1302.

Defalque, R. J. (1961). Pharmacology and toxicology of trichloroethylene; a critical review of the world literature. Clin. Pharmacol. Ther., 2, 665-688.

Dillon, J. B. (1956). Trichloroethylene for the reduction of pain associated with malignant disease. Anesthesiology, 17, 208-209.

Enderby, G. E. H. (1944). The use and abuse of trichloroethylene. Brit. med.J., 2, 300-302.

Firth, J. B., and Stuckey, R. E. (1945). Decomposition of trilene in closed circuit anaesthesia. Lancet, 1, 814-816.

Glaser, M. A. (1931). Treatment of trigeminal neuralgia with trichlorethylene, J. Amer. med. Ass., 96, 916-920.

Goldstein, N. P., Gibilisco, J. A., and Rushton, J. G. (1963). Trigeminal neuropathy and neuritis. Ibid., 184, 458-462.

Grandjean, E., Münchinger, R., Turrian, V., Haas, P. A., Knoepfel, H-K., and Rosenmund, H. (1955). Investigations into the effects of exposure to trichlorethylene in mechanical engineering. Brit.J. industr. Med., 12, 131-142.
Hewer, C. L. (1943). Further observations on trichlorethylene. Proc. roy. Soc. Med., 36, 463-465.

- , and Hadfield, C. F. (1941). Trichloroethylene as an inhalation anaesthetic. Brit. med.J., 1, 924-927.

Humphrey, J. H., and McClelland, M. (1944). Cranial-nerve palsies with herpes following general anaesthesia, Ibid., 1, 315-318.

Hunter, D. (1944). Trilene hazard. Ibid., 1, 341.

Jackson, D. E. (1934). A study of analgesia and anesthesia, with special reference to such substances as trichlorethylene and vinesthene (divinyl ether), together with apparatus for their administration. Curr. Res. Anesth., 13, 198-204.

Kalinowsky, L. (1927). Toxische Lähmungen des Trigeminus. $Z \mathbf{b l}$. ges. Neurol. Psychiat., 47, 477.

McAuley, J. (1943). Trichlorethylene and trigeminal anaesthesia. Brit. med.J., 2, 713-714.

Oljenick, I. (1928). Trichlorethylene treatment of trigeminal neuralgia. J. Amer. med. Ass., 91, 1085-1087.

Plessner, W. (1915). Uber Trigeminuserkrankung infolge von Trichloräthylenvergiftung, Neurol. Zbl., 34, 916-918.

Sen Gupta, P. C. (1943). Observations on the neuropathic sequel of diamidino-stilbene therapy in kala-azar. Indian med. Gaz., 78, 537-543.

Siegel, J. (1967). Personal communication.

Smith, G. W., and Miller, J. M. (1955). The treatment of tic douloureux with stilbamidine, Bull. Johns Hopk. Hosp., 96, 146-149.

Stüber, K. (1931). Gesundheitsschädigungen bei gewerblichen Verwendung des Trichloräthylens und die Möglichkeiten ihrer Verhütung. Arch. Gewerbepath. Gewerbehyg., 2, 398-456. 